\title{
Erratum to: The Sesquiterpene Lactone, Budlein A, Inhibits Antigen-Induced Arthritis in Mice: Role of NF-KB and Cytokines
}

\author{
Ana C. Zarpelon, ${ }^{1}$ Victor Fattori, ${ }^{1}$ Fabricio O. Souto, ${ }^{2}$ Larissa G. Pinto, ${ }^{2}$ Felipe A. Pinho-Ribeiro, ${ }^{1}$ \\ Kenji W. Ruiz-Miyazawa, ${ }^{1}$ Walter M. Turato, ${ }^{2}$ Thiago M. Cunha, ${ }^{2}$ Fernando B. Da Costa, ${ }^{3}$ \\ Fernando Q. Cunha, ${ }^{2}$ Rubia Casagrande, ${ }^{4}$ Nilton S. Arakawa, ${ }^{4}$ and Waldiceu A. Verri Jr ${ }^{1,5,6}$
}

\section{Erratum to: Inflammation (2017)}

https://doi.org/10.1007/s10753-017-0642-1

Unfortunately, the original publication of this article contained mistakes, and the authors would like to correct them. The corrected details are given below:

Molecular structure of Budlein A (Fig. 1): In the structure of Budlein A, a carbonyl group in the ester moiety is missing (at the carbon $1^{\prime}$ ) and the geometry of the structure was incorrect. The correct Fig. 1 is now presented herein.

The online version of the original article can be found at https://doi.org/ 10.1007/s10753-017-0642-1

${ }^{1}$ Departamento de Ciências Patológicas, Centro de Ciências Biológicas, Universidade Estadual de Londrina, Rod. Celso Garcia Cid PR 445, Km 380 Cx. Postal 10.011, Londrina, Parana 86051-990, Brazil

${ }^{2}$ Department of Pharmacology, Ribeirão Preto Medical School, Preto, University of São Paulo, Avenida Bandeirantes, 3900, Ribeirão Preto, São Paulo, 14049-900, Brazil

${ }^{3}$ University of São Paulo, School of Pharmaceutical Sciences of Ribeirão Preto, Laboratory of Pharmacognosy, Av. do Café, s/n, Ribeirão Preto, São Paulo, 14040-903, Brazil

${ }^{4}$ Departamento de Ciências Farmacêuticas, Centro de Ciências da Saúde, Universidade Estadual de Londrina, Londrina, Paraná 86038-350, Brazil

${ }^{5}$ Departamento de Patologia, Centro de Ciências Biologicas, Universidade Estadual de Londrina, Rod. Celso Garcia Cid Pr 445,KM380, Cx. Postal 10.011, Londrina, Parana 86057-970, Brazil

${ }^{6}$ To whom correspondence should be addressed at Departamento de Patologia, Centro de Ciências Biologicas, Universidade Estadual de Londrina, Rod. Celso Garcia Cid Pr 445,KM380, Cx. Postal 10.011, Londrina, Parana 86057-970, Brazil. E-mail: waldiceujr@yahoo.com.br

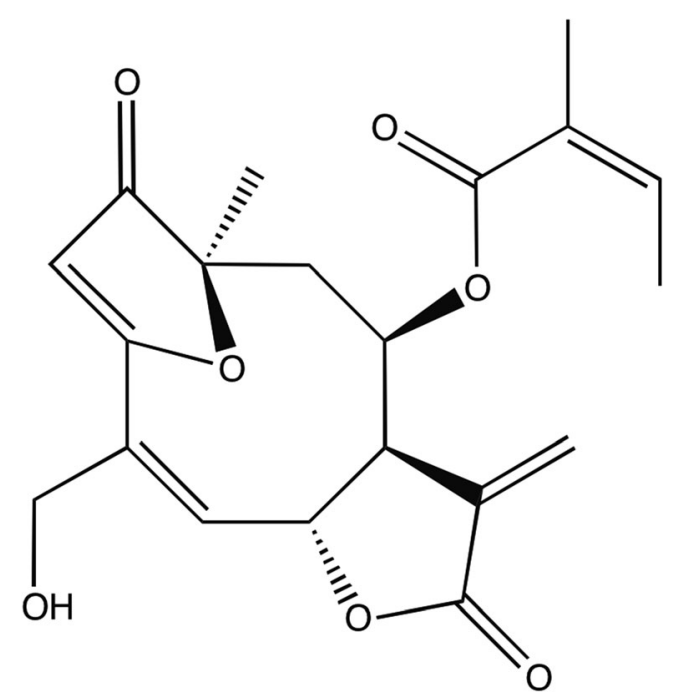

Prof. F. B. Da Costa address and family name: Prof. Fernando B. Da Costa correct address (number 3 of the list of address) is: "University of São Paulo, School of Pharmaceutical Sciences of Ribeirão Preto, Laboratory of Pharmacognosy, Av. do Café, s/n, Ribeirão Preto, São Paulo, 14040-903, Brazil". Furthermore, his family name was incorrect. The correct family name should read as "Da Costa", with upper-case "D" and not lower-case "d" as initially provided. These corrections are presented herein.

The authors apologize for potential issues raised by these mistakes. 